\title{
An Evaluation of Rural Tourism Potential for Rural Development in Kenya
}

\author{
Collins Ouma Agayi Dr. Elif Gündüz * \\ Department of City and Regional Planning, Faculty of Architecture and Design, Konya Technical University, \\ Konya, Turkey
}

\begin{abstract}
All over the world, tourism continues to be an integral part of economic development by contributing to countries' gross domestic product (GDP), earning foreign exchange, creating job opportunities among other significant contributions. There is a need for increased diversification of tourism market away from the traditional ones like coastal and wildlife tourism. Over-reliance on mass tourism especially coastal based tourism also has negative degradation impacts on the environment, destruction and exhaustion of tourism products due to overexploitation. The need to improve tourists' experiences in the destinations has led to increased calls for diversification of tourism products, thus shifting focus to the rural areas. Many potential tourism products like cultural heritage, archaeological sites and the good natural sceneries in rural areas remain unexploited or underexploited. This proposed study aims to deliberate on whether the sustainable development is possible for rural tourism in Kenya. This study examines the existing strategies employed by the Kenya government and other stakeholders in the tourism sectors, to determine areas of weakness that would require interventions. By conducting a SWOT analysis of the tourism potential in Kenya, this paper seeks to identify the untapped tourism potentials in rural Kenya and make necessary proposals for exploitation, to increase the competitiveness of Kenya tourism sector globally. Finally, the research establishes the general challenges facing the tourism sector in Kenya that have or have the potential to limit optimum operation and development in the sector. The research relies on secondary sources of data including research articles, government reports, academic documents and non-governmental organizations research works for a better understanding of the tourism sector in Kenya.
\end{abstract}

Keywords: Cultural heritage, Tourism destination, Rural development, Rural Tourism, Tourism products.

DOI: $10.7176 / \mathrm{JAAS} / 63-05$

Publication date: April $30^{\text {th }} 2020$

\section{Introduction}

The development and sustainability of tourism in a region is closely related to the potentials and different perspectives about tourism. The rapidly growing tourism industry diversifies and enriches tourism destinations in line with the demands of the visitors. Rural tourism diversity has been one of the tourism diversities of recent times with this different point of view. The tourism industry is a very essential sector of the Kenyan economy, contributing approximately $11 \%$ of the country's Gross Domestic Product (Mayaka \& Prasad, 2012). It is also important as it supports both local and national economies by creating jobs to many, earning the country important foreign exchange, attracting international and regional investments among others. However, lack of diversification of Kenyan tourism remains a major challenge in Kenya, with African Safari and Beach tourism being the main tourism products offered by Kenya to the tourism market (GOK, 2018). The tourism potential in the rural areas of Kenya has largely been ignored or under-exploited as the government focuses on the two traditional and wellestablished tourism products. Weidenfeld (2018) points out the competitive advantages of rural areas in tourism by highlighting the combination of natural and cultural values in the rural areas which have the potential to earn income for local if exploited. In Europe, rural tourism has been significant in regenerating the rural economy by supporting socio-economic development programs in the peripheral rural areas that have been experiencing a decline in the traditional agricultural sector (Sharpley, 2002). Diversification of tourism not only increases the product varieties available in the destination for the international and regional markets, but it also acts as a counter to mass tourism which is mainly coastal-based, therefore, offering a more balanced and sustainable tourism growth within a country. The Kenya rural area has a lot of cultural heritage, historical and archaeological sites that are yet to be exploited for the benefit of the country and diversification of tourism sector.

This study examined the challenges facing the tourism sector in Kenya that hinders its competitiveness in the regional and international markets. It was determined that the lack of diversification of tourism products was a major factor affecting the quality and the variety of products offered to the international market. This lack of diversification was established to be a result of inadequate efforts to exploit tourism potential in rural areas including cultural heritage and archaeological tourism potential. The research also analysed the various strategies put in place by the government to increase the competitiveness in the tourism sector including infrastructural investments in the sector. Finally, the study proposed measures that could help reduce the weaknesses in the tourism sector in Kenya while increasing its competitiveness for sustainable tourism growth in the country. 


\section{Rural Development and Tourism in Kenya}

Rural development as a concept refers to policy and project interventions targeting rural areas and intended to foster social and economic changes and improve the human conditions in the rural areas by addressing the issues of agriculture, peasant economy and rural politics (Bebbington, 2001). Many pieces of literature have been written concerning the evolution of the concept 'Rural Development' which varies depending on the regions and the period covered. The increasing complexity of problems for development in rural areas has revealed the need for a multifaceted development approach in these areas. The insufficiency of sectoral perspective in rural area policies has made it compulsory to be handled with a planning perspective with both sectoral and spatial dimensions. Tourism, alongside other sectors of the economy, plays a huge role in the economic growth and development of a country. Rural-based tourism activities also spur economic growth in the rural areas producing similar domino effects to the regions around and to the national economy. The concept of 'rural tourism' and how it contributes to the development in rural areas are discussed in this section.

\subsection{The Rural Development}

Rural area' is a term used globally by policymakers, researchers as well as internal bodies like the agencies of the United Nations, the European Union among others. The standard international definition of the concept hasn't been adopted to date and countries and various bodies tend to use their own definition which varies from one country to another. While some countries classify their rural areas based exclusively on population threshold, others do consider other different factors like socio-economic characteristics, natural features, the spatial dimension of social organization, etc. The majority of European countries and the Organization for Economic Cooperation and Development (OECD) use population density as the main factor to delimit rural areas. A region is therefore categorized as rural if more than $50 \%$ of the inhabitants occupy the rural parts of the municipalities, which are areas having at least 150 persons per square kilometers (Perlín, 2010).

The United Nations through the UN Principles and Recommendations leaves it for individual countries to define a rural area as reaching a consensus on a single global definition would be impossible due to differences in global characteristics of rural and urban areas (Dijkstra \& Poelman, 2014). Other bodies and agencies delimit rural areas based on the main economic activities in the area. As a UN Agency specialized in the development of rural areas, Food and Agricultural Organization (FAO) associates rural areas with agricultural activities and where a considerable percentage of the population is employed in the agricultural sector (Pizzoli \& Gong, 2007).

As Bramwell (1994) stated 'rural areas can be under especial threat because of their physical fragility and their cultural fragility due to their weakened cultural and political condition after years of economic change and decline with power flowing to urban areas'.

The rural development concept got traction after the second world war due to perverse effects of economic development initiatives that promoted social inequality by not distributing generated wealth equally, increased territorial inequality as the rural and non-industrialized urban areas were ignored thus suffering depression and exodus, and environmental damage in England (Calatrava, 2016). Specific models of economic development and strategies geared towards achieving greater territorial equality were therefore initiated with the 'Rural Development' strategy specifically targeting economic revitalization and development in rural areas. In the USA, efforts to aid rural areas struggling with low incomes and low living standards due to the 1929 Economic Depression began in 1932 when the Federal Emergency Relief Administration and later the Farm Security Administration and the Work Projects Administration started assisting rural families and households (Cowan, 2010). In the post-world War II period, widespread poverty in rural areas especially among the farmers made the Under Secretary for Agriculture, True D. Morse, to begin Rural Development programs in 1955 aimed at assisting the low-income farmers in the rural areas. There was however a shift away from agriculture to rural revitalization in the 1960s with the decline of agriculture as the rural dominant activity. Rural development, therefore, focused on other sectors including the provision of adequate housing, infrastructure development, medical care, creation of employment, poverty issues among others (Cowan, 2010).

\subsection{Rural Tourism}

As discussed earlier, in the western world the transformation of rural areas towards tourism and leisure-related services has been clearly evident, but tourism has also been increasingly seen as a relevant tool for solving the rural problems in developing countries recently(Binns \& Nel, 2002; Odendal \& Schoeman, 1990; Rogerson, 2012a). Rural areas, especially in developing countries, rely too much on agriculture as the main economic driver. There is, therefore, a need to diversify the economy of rural areas to achieve sustainability in rural development. This could be achieved through rural tourism. According to Bramwell (1994), rural tourism is multifaceted and includes all the activities taking place in the countryside like adventures, sports, heritage, arts, education, health, etc. and not necessarily farm-based tourism activities. Pedford (1996) as cited in (Su, 2011) further expands the concept of rural tourism to include different aspects of culture, family values and traditions, rural customs and beliefs in the countryside. Demand for 'rural tourism' is therefore directly attributed to the rurality of the 
countryside environment. This is further emphasized by Sharpley and Roberts (2004), who argue that people visit rural areas because of their uniqueness, thus qualifying rural tourism as an independent tourism type. However, it must be known that rural tourism host communities are most vulnerable to economic shock and environmental hazards that could disrupt livelihoods and community well-being (Amir, Ghapar, Jamal, \& Ahmad, 2015). The uniqueness of tourism in different rural areas means that efforts to develop tourism policies should therefore, respond to specific needs of particular rural areas to satisfy the consumers' needs while preserving the physical and cultural resources upon which the rural tourism depends on by encouraging sustainable tourism practices (Anderson, Bakir, \& Wickens, 2015). These sustainable tourism practices are what Swarbrooke (1999) describes as the measures that ensure economic viability of tourism in the rural area without causing damage to the physical environment, and the social tenets of the host community which would otherwise compromising the ability of the future generations to benefit from the tourism resources. So, it could be said that tourism development in rural areas, is actively used for economic diversification and opening up new ways to generate income and employment in the developing world nowadays (Mafunzwaini \& Hugo, 2005; Rogerson, 2012b). Socially, rural tourism is instrumental in the repopulation of otherwise deserted rural areas, building cohesion in communities by improving social contacts among members of the community, and improving and maintaining key local social services like education facilities, health centers and roads (Cánoves, Villarino, Priestley, \& Blanco, 2004). Measures should be taken to reduce the negative environmental impacts attributed to tourism as various previous studies have pointed out that all forms of tourism have a varied degree of negative socio-cultural and environmental impacts in the destination areas (Roberts \& Hall, 2001; Sharpley \& Sharpley, 1997). There is real threat of destruction or a diminishing value of tourism facilities if they are not well protected from the large numbers of tourist visiting or well maintained. Besides, a large number of tourists in the rural areas is likely to results into pollution of the physical environment through poor waste disposals, too much traffic could also cause air pollution while the large number of tourists converging at specific points may cause too much noise. A balance between environmental protection and drawing maximum benefits from the tourism activities in the rural areas should therefore be found. This could only be achieved through management of both supply and demand as tourism is both supply-led and demand-driven (Liu, 2003). Therefore, an inflow of tourists beyond the capacity is likely to result into net loss economically, socially and environmentally.

\section{Rural Development and Tourism in Kenya}

The development of tourism in rural areas and poor communities generally involves inequalities and inequalities between inclusion and exclusion and different values, goals and land uses among development and social actors(Paniagua \& Moyano, 2007). The UN WTO emphasises that tourism development in Africa is particularly important in the fight against poverty (Saarinen \& Lenao, 2014). In Kenya, there is no clear definition of rural areas. However, urban areas are clearly defined and that which is not urban can be considered to be rural. Kenya defines an urban area as areas with a minimum population of 2000 and with good infrastructures like schools, hospitals, markets, etc. (UN, 2019). Any area outside this definition is thus considered to be rural. Kirori (2015) gives the rural concept in Kenya an economic perspective where the sector is mainly dominated by agricultural activities responsible for the source of livelihood to least 75\% of Kenya's population. Besides, Kirori (2015) points out that Kenya rural accounts for at least $60 \%$ of the total Kenya population.

In Kenya, the government adopted the policy of rural decentralization soon after independence to achieve more balanced development and sustainable livelihood by households in rural areas. The government, as pointed out by Kirori (2015), rolled out eight rural development programs including rural health, roads, primary education, water, housing, trade centers, and employment and rural funding. To deliver on its program, the government initiated rural development strategies called 'National Development Plans'. According to Kirori (2015), by 2008, the government had formulated nine such plans to be implemented in rural areas. The (1970-1974) plan was referred to as "Rural Development" and was aimed at improving the social and economic condition of all Kenyans by focusing on rural areas. The third plan (1974-1978), focused on employment and improving living standards in rural areas. Further, 1979-1983 was produced to tackle the problem of poverty in rural areas and diversify production in the rural. The (1984-1988) plan transferred rural development programs to the district level for better resource mobilization and equitable development while (1989-1993) plan encouraged further decentralization to reduce wealth concentration in towns. The (1994-1996) plan emphasized the importance of national and local partnerships for development. The (1997-2001) highlighted implementation strategies and the strategic significance of the location of light industries in the rural. It was further aimed at the increasing linkage between urban areas and rural areas. The final plan (2002-2008) encouraged community participation and consultation in planning and implementation processes for effective resource allocation and use. The rural areas are often isolated and have less economic life compared to the urban areas. The existence of better and more opportunities in urban areas has resulted in a mass exodus from rural areas and therefore, they are relatively sparsely populated compared to the urban areas. Rural development is therefore important to revitalize these rural areas and make them important centers of production that can attract population and investment. Such initiatives are also important as they ensure 
balanced growth and development among the urban and rural areas with investments in all important sectors like education, infrastructure, health, agriculture, industry, etc. The rural economy thus becomes diversified as opposed to relying entirely on agriculture.

Being an important and a leading tourist destination in the Sub-Saharan Africa, Kenya has exploited tourism potentials to its advantage to spur socioeconomic development in the country. This is reflected by the level of tourism infrastructural development, branding of tourism sector for international markets, diversification of the tourism products in Kenya among other strategies to make Kenya more competitive in the region. The location of Kenya in the regional context and the various strategies employed by the Kenyan government to improve tourism in the rural areas for socioeconomic development are discussed in this section.

\subsection{Locational Context of Kenya.}

Kenya is a sub-Saharan country of Africa, located on the Eastern part of the continent, bordering six countries: Somali to the East, Tanzania to the South, Uganda to the West, South Sudan and Ethiopia to the North. According to the 2019 population census, Kenya with a total population of 47,564,296 (ROK, 2019a), consist of 23,548,056 males, 24,014,716 females and an average household size of 3.9. A majority of the population $(32,732,596)$, lives in the rural parts of the country while the remaining $14,831,700$ occupying the urban areas, thus, Kenya is dominantly rural (ROK, 2019b). The population density is however highest in the major urban areas like Mombasa and Nairobi with population densities of 5,495 and 6,247 persons per square kilometres respectively against the average national population density of 82 persons per square kilometre. For ease of governance and distribution of national resources, Kenya is divided into 47 devolved units, referred to as counties. These counties have separate administrative units called county governments with a county executive headed by an elected governor. Although not autonomous units, the constitution describes the two levels of government as distinct but interdependent and therefore work in corporation and collaboration (ROK, 2010). About 2.6 million of the economically active population (22.3 million) are unemployed and therefore looking for jobs with women accounting for $50.2 \%$ of the total working population in Kenya (ROK, 2019c). Agriculture is the dominant economic activity and source of livelihood for the rural communities in Kenya, practised by 6.4 million households of the total 12.1 million households inhabiting the rural parts of the country. The main crops grown by farmers are maize and beans. A total of 4.7 million and 0.1 million also engaged in livestock keeping and fishing respectively. Kenya is also a diverse country of many types of cultures, more than 44 different tribes, religions and races. This makes the rural areas potential for rural based tourism activities like cultural heritage and nature tourism.

Besides being the gateway to East Africa, owing to its strategic location on the horn of Africa and access to the Indian ocean, Kenya is also hosting international organizations and United Nations agencies like UN-Habitat and UNEP, thus exposing it to the world for potential tourism markets. The location of Kenya within regional and African context is shown if figure 1 below.

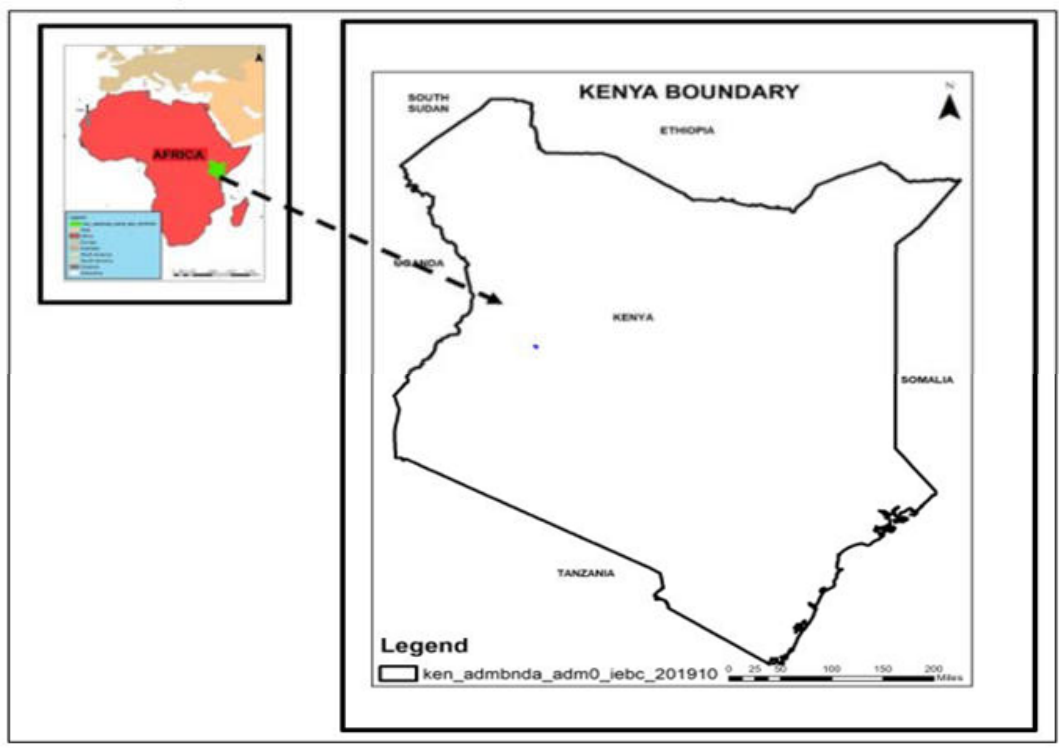

Figure 1. African and regional local context of Kenya (Author, 2020).

Kenya located at the horn of Africa competing other countries for same international market for tourism.

3.2 Kenya Rural Tourism Strategies

Rural tourism hasn't been exploited to the maximum potential in Kenya. Despite this, the government strategies 
to the tourism industry in Kenya focus on traditional tourism sources like wildlife and beach tourism intending to attract more international tourists but less focus is paid on the rural tourism markets whose potentials are yet to be realized. The overall government strategies to improve the tourism sectors in Kenya are addressed in the national tourism policy, national tourism blueprint among other government documents and includes measures like revamping and improving the tourism infrastructure, marketing of the sector, improving the security among other strategies discussed below;

3.2.1 Improving the Infrastructure

Countries wishing to achieve greater results and more economic development invest significantly in the general infrastructures (Jovanović \& Ivana, 2016). As S. Smith (1994) points out, the experience and level of satisfaction of a tourist could highly be influenced by the availability quality of tourism infrastructure in a destination or lack of it. Good quality airports increase the comfort level of tourists by ensuring the good transition from the airport to the tourism destination a country, besides, good road networks increase the accessibility of the destination points thereby encouraging more tourism (Seetanah et al., 2011). In Kenya, poor infrastructure is a major factor in reducing the competitiveness of Kenya tourism market. Congestion at the waiting lounges of main airports in Kenya, dilapidated counters, delays in baggage processing at the carousel among other problems was registered by the tourists in an exit survey $(\mathrm{GOK}, 2013)$. Bad experiences by the tourists would have negative impacts on future tourism arrivals. The National Tourism Blueprint, therefore, proposes an improvement to the existing service delivery chain at the airports which are likely to compromise the passenger experience (GOK, 2017). As part of the National Blueprint implementation strategy on infrastructure, the Tourism Agenda 2018 - 2022 proposes refurbishment and expansion of local airports capacity to handle larger aircrafts and receive direct flights(GOK, 2018). The government also intends to reduce the mobility period between the mobility corridors (between destinations or between airport and destination) in compliance with the internationally accepted standards of the golden two hours for international leisure tourists by expanding and upgrading the trunk roads and the super-highways (GOK, 2017). Other infrastructure upgrading programs undertaken by the government include upgrading of Mombasa waterfront by redesigning and re-planning the area to an reflect the iconic international standard seafront.

3.2.2 Marketing Strategy

Sub-Saharan Africa has suffered negative publicity due to cases of violent conflicts, droughts, corruption, political instabilities, extreme poverty among other problems which have earned it the title 'dark continent'(Avraham \& Ketter, 2017). Lepp, Gibson, and Lane (2011) further point out that political instability and threats of terrorism as among factors discouraging tourists from visiting countries in the continent. Kenya, being one of the countries in Africa has suffered these negative stereotypes and biases as argued by Muhwezi, Baum, and Nyakaana (2016) that affected countries must first deal with the negative image at the destination to achieve the desired competitive advantage. Marketing the tourism destination or as referred to as 'destination marketing' by Kozak and Buhalis (2019) is, therefore, an effective tool to boost the country's image globally for effective access to targeted international markets. As part of its strategy to sell Kenya abroad as the best tourist destination in the region, Kenyan government has adopted various marketing and tourism branding strategies like implementation of Brand Kenya Initiative, hosting of international conferences, digital marketing, global campaigns, deploying a $360^{\circ}$ communication plan, Implement the Safari Innovation \& Development Program (SIDP) and Kenya Tourism Festivals (GOK, 2018, 2019).

3.2.3 Quality Tourism Products Development and Diversification Strategy

The number of tourists visiting a destination is directly proportional to the previous destination experience and quality and diversity of primary products being offered (Jafari, 1982). Good quality production is, therefore, key to offering good experiences to the tourists. However, Benur and Bramwell (2015) argue that the development of the primary tourism product in a destination could be very complex as it involves many elements. Ensuring good experience of the tourism products by tourists at the destination is therefore very important as J. B. Xu (2010) see these experience as central to the choice of a destination and satisfaction derived from it. Kenya experience both diversification and quality deficiency in its primary tourism products as they rely mainly on African Safari and Beach destinations pointing to a lack of diversification (GOK, 2018). Lack of diversification is also seen in the underutilization of the parks with only seven parks being visited by $80 \%$ of tourists despite Kenya having 29 national parks (GOK, 2017; World-Bank, 2010). The quality of the hotels, which are part of the tourism products and responsible for overall experience by the tourists, is also not satisfied with only $18 \%$ of the total hotels being of 4-5 star level (GOK, 2010). This lack of diversification and low-quality products affects the competitiveness of Kenya as a tourist destination as argued by Benur and Bramwell (2015) that the ability of a destination to compete with other destinations offering more diversified products is reduced. To achieve diversification of products, the government with the involvement of private sector and other stakeholders intends to introduce new products in the core regions/experiences (Maasai Mara/Amboseli and Coast Region/ African Safari and Beach tourism), to fix the quality of existing products in the core regions, introduce new products in the non-core regions (less attractive areas) and fix the support functions like roads, hotels, and airports in these non-core regions (GOK, 
2017). To increase diversity, the ministry in charge of tourism intends to introduce and promote Avitourism (birding), photography, voluntourism (communities and wildlife/nature conservation) and flora, scientific research, entomology and film as new tourism products which are unexploited potentials in the rural areas (GOK, 2018).

3.2.4 Tourism Sector Investment

Investing in the tourism industry could lead to the production of other goods and services resulting in higher profits. The investment in the tourism industry may come from other regions within a nation but outside the destination regions or in the form of foreign direct investment (FDI). C. Xu, Jones, and Munday (2019) argue for inward investment because multinational firms or those located regionally have superior technologies, more assets, better managerial skills and could bargain better because they have got product relocation flexibility and incur less cost in terms of capital. Similarly, Proença and Soukiazis (2008) support international investment in the tourism sector by linking the ability of an economy to benefit from tourism to the availability of investment (international) which is necessary for infrastructural development as well as provision of necessary services to tourists like accommodation, transportation and, safety. The Kenyan government, therefore, seeks to boost investment in the tourism sector by providing tourism incentives that would attract foreign investors. To attract tourists, the government would link the local hotels to the international brands for partnership thus boosting their stature internationally(GOK, 2018). Other measures to be taken by the government includes: setting up a 100 million US dollars for affordable loans to the hotel owners to refurbish their hotels, construction of cruise ship terminal, removing investment blockages, promotion of Kenya as an investment destination among others (GOK, 2019).

\subsection{Rural Tourism Potentials in Kenya}

Kenya is endowed with many tourist attraction resources including the ocean and lake beaches in Mombasa, Lamu, Malindi, and Kisumu, deserts (Chalbi and Nyiri), beautiful rain forests like Kakamega forest, grasslands, coral reefs at the Coast, islands like Mfangano, The Great RiftValley, beautiful tribal cultures among others. The majority of these natural resources aren't utilized for international tourism except for the beaches on the Coast of Kenya. Besides this, wildlife continues to be a major tourist attraction in Kenya. According to World-Bank (2010), besides the big five animals, Kenya has more than 500 and 359 birds and animal species in a 47,674 square kilometers pieces of land of national parks, game reserves, wildlife sanctuaries and wildlife conservancies spread across the country. There is however underutilization of these resources as most of them in the rural areas are not marketed and therefore attract few tourists as $80 \%$ of the tourists do visit 7 parks only, therefore leaving all the other parks and reserves underutilized (GOK, 2017; World-Bank, 2010). With large bad species, Kenya has the potential to be a tourist destination for bird watchers and trekking activities around Mount Kenya. Flamingos, shown in figure 2. have attracted a significant number of tourists to Kenya being an important tourist attraction in Nakuru County.

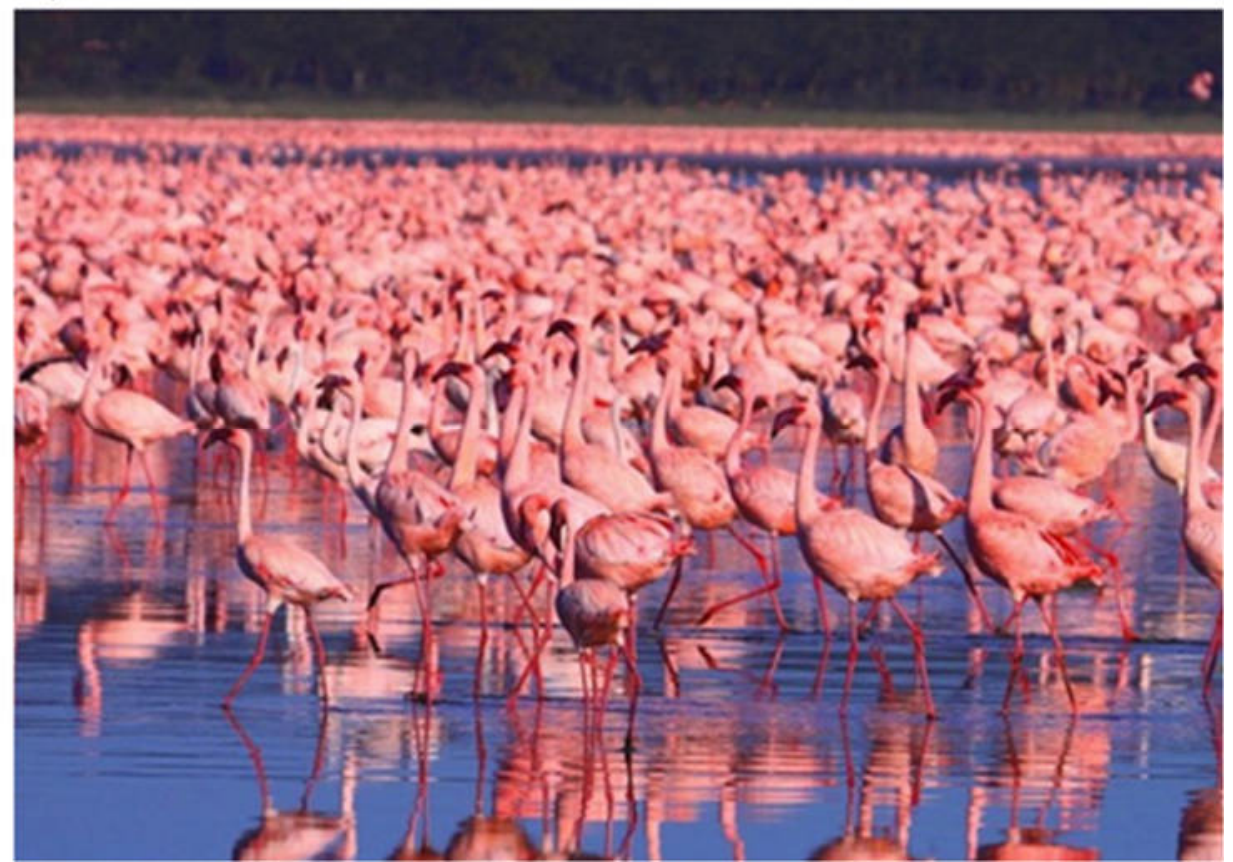

Figure 1. Lake Nakuru National Park (SED Adventures, 2020).

Flamingos found in Lake Nakuru National park are a part of the more than 359 birds' species in Kenya. 
Besides the natural resources, Kenya, especially the rural areas that remain underexploited have a huge cultural heritage, historical and archaeological assets that could attract many tourists. The current world tourism trend is such that there is a shift of tourism behavior, motivation and experience from traditional tourism to the cultural and archeological based tourism (Nyaupane, White, \& Budruk, 2006). Therefore, instead of relying mainly on wildlife and beach tourism, Kenya would become a popular tourist destination if it exploited her rich cultural heritage and would compete effectively with her regional competitors like Mauritius, Botswana, and Seychelles whose tourism markets are very much diversified (Irandu \& Shah, 2016). As cited by M. K. Smith (2015) in Irandu and Shah (2016), cultural tourism types include museums, monuments, archaeological sites, theatres, cultural centers, religious sites, indigenous communities, arts and crafts, sporting, languages among others. Kenya indeed has many of these cultural sites. However, with less marketing, the sites are less visible to the international market thus attracting fewer tourists. Important cultural heritage sites in Kenya are the old Swahili settlements like Takwa, Gede Jumba la Mtwana dating from eighth century until seventeenth century and located at the Coast of Kenya, Fort Jesus which is a world-famous old military monument built by the Portuguese in Mombasa, historical religious sites like the Chapel Mosque and Krapf Memorial Museums. There are also archaeological and paleontological sites in the Great rift valley of Kenya. Kariandusi and Olorgesailei are homes to early stone age man while Koobi Fora is a World Heritage site where early hominids were discovered (Farah, 2006). The rich and colorful tribal traditional cultures like the Maasai culture also offers a very good tourism potential especially in the rural. The rich and colorful tribal traditional cultures like the Maasai culture also offer very good tourism potential especially in the rural. The rich cultural heritage in Kenya is also reflected in the more than 44 ethnic groups with distinct languages and culture, and which originated from different regions in Africa more than 4000 years ago but today existing side by side (World-Bank, 2010). If these cultural heritages are exploited, it could offer an effective alternative to the traditional beach and wildlife tourism in Kenya.

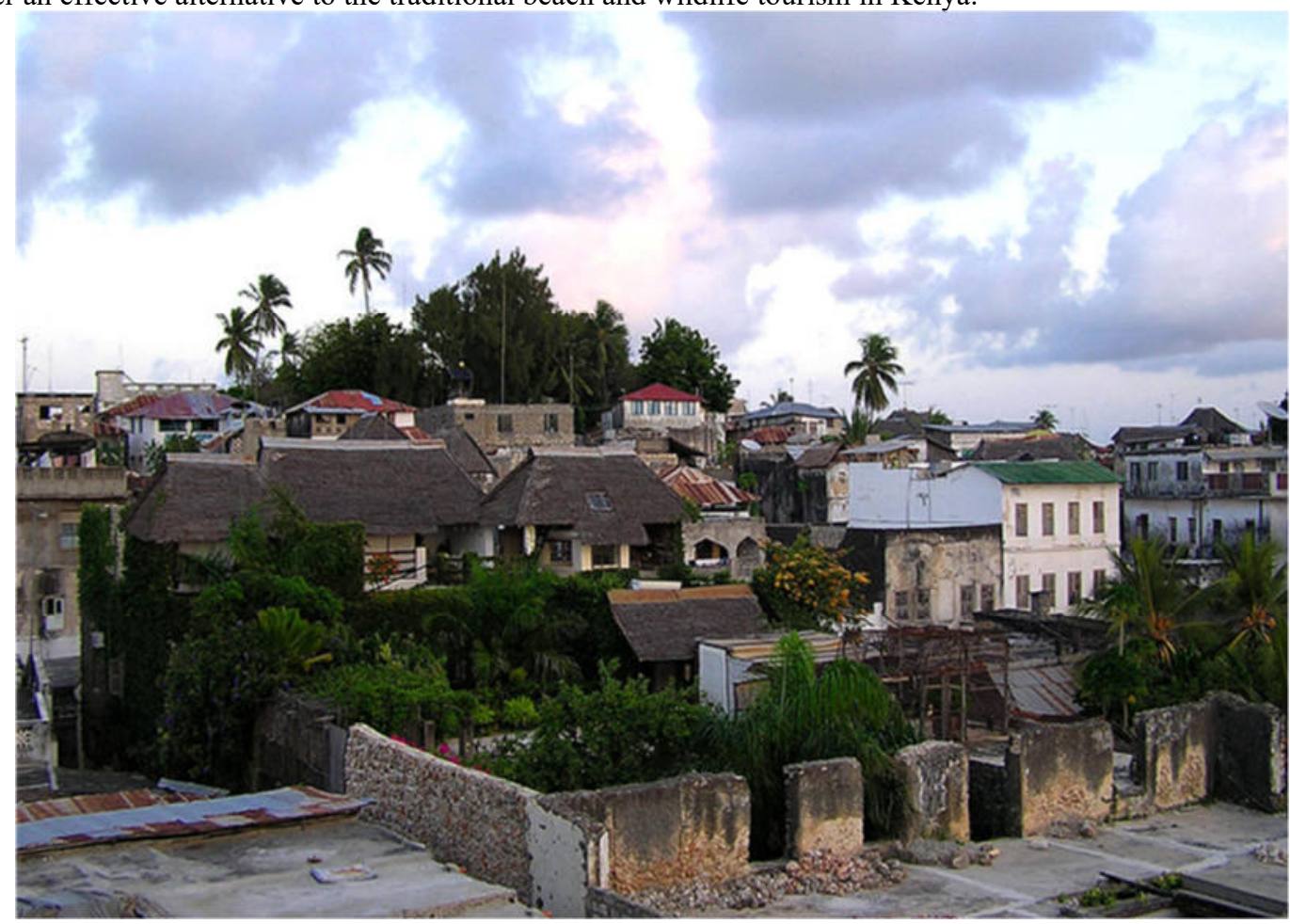

Figure 2. Lamu Old Town (Chantal, 2018)

\subsection{Kenya Rural Tourism SWOT Analysis.}

An analysis of government reports, previous research works, and other documents reveals the tourism areas that Kenya does excel in (Strengths), the weak links preventing Kenya from realizing its maximum tourism potential and therefore, reduced its competitive advantages vis-à-vis other regional and internal competitors (Weaknesses), external conditions and factors which could guarantee Kenya an edge in tourism sector over other regional and international competitors in the sector (Opportunities) and, the external factors that could harm the tourism sectors leading to its potential collapse. The findings of the analysis establish that strength and opportunities of tourism sector in Kenya outweigh the external threats and the weaknesses in the sector. Maximum and efficient exploitation of the opportunities and efforts to address the weaknesses would therefore make Kenyan market more competitive 
than regional competitors, especially if the tourism potential in the rural areas are well identified and marketed to the international tourism markets. The factors (SWOT) are summarized in table 1. below:

Table 1. Kenya tourism potential SWOT analysis

\section{STRENGTHS}

- Devolution strengthens tourism at local level.

- Presence of beautiful beaches with clean and calm waters of Indian Ocean along Kenyan Coast.

- One of the best wildlife safari destination in the world with unique wildlife.

- Strategic location of Kenya vis-à-vis regional competitors most of which are landlocked. Kenya is the gateway to East Africa.

- Quality international air transport connections, reputable airline (Kenya airways) and international airports.

- Relative calm and political stability in the country.

- A very welcoming and warm population that's very friendly to visitors.

\section{OPPORTUNITIES}

- Strategic location of Kenya and global reputation of Nairobi.

- Kenya is yet to access many international markets.

- Having a regional aviation hub receiving direct flights from many countries.

- Many untapped tourism potential that could boost tourism e.g. domestic tourism.

- Kenya is headquartering many international organizations like UNEP, UN Habitat etc.

\section{WEAKNESSES}

- Poor state of roads between destinations in the country reduces comfort.

- Traffic congestion costs time.

- Kenya tourism sector is highly seasonal.

- Lack of product diversification.

- Over involvement of international players like tours operators reduces benefit to local economy.

- Poor quality services relative to international competitors e.g. Accommodation.

- Poor market diversification.

\section{Challenges to Rural Tourism Development in Kenya}

Kenya has faced various factors undermining its growth and development despite being an important sector of the Kenyan economy and contributing between $10 \%$ and $13 \%$ to the gross domestic product within the last two decades (Mayaka \& Prasad, 2012). Challenges discussed in this section are not unique to tourism in the rural areas but the general tourism industry in Kenya.

\subsection{Preservation of Culture}

Although sharing of local culture by the hosts with the visiting guests has positive effects like a stronger sense of identity, employment, community pride, cultural exchange, revitalization of the local cultures among other benefits, a lot of emphases should be put on cultural conservation so as not to deplete and destroy the cultural heritage. While the growth of cultural tourism has brought economic development to the rural communities, when the demand outweighs the supply, there is a risk of depletion of culture and the loss of value due to less protection. As pointed out by Rotich (2012), while an increase in cultural tourism demand may have economic benefits, it loses out on quality because increased demand sometimes brings about a dramatic degeneration of the finished product (culture). According to Wishitemi and Okello (2003), in Kenya, protection, and maintenance has focused more on the biological biodiversity like national parks, wildlife sanctuaries and areas endowed with natural resources for economic benefits. Less focus has however been trained on the cultural resources.

\subsection{Political Instability and Insecurity}

Whereas significant efforts have been made to improve domestic tourism in Kenya, Kenya's tourism sector still relies heavily on international arrivals. The number of internal arrivals in Kenya IN 2018 was 2.02 million up from 1.4 million the previous year according to figures provided by the tourism and wildlife ministry. This represents an increase of $33.33 \%$ growth in one year. This increase was mainly attributed to the political stability in Kenya after the popular handshake between the president and the opposition leader and the improved security in Kenya (GOK, 2019).

The threat of political instability to international tourism can also be seen in the decline of international arrivals from the developed countries from 1.8 million in 2011 to 1.5 million in 2013 . The biggest decline was recorded among the visitors from the developed countries representing a $17 \%$ fall. This decline was mainly attributed to the Kenya intervention in the Somali conflict to stop terrorism after several high profile kidnappings 
of the European tourists in Kenya by the Somali-based terror organization, Al-Shabab (Buigut, 2018). Also, the Kenya electioneering process has had an impact on the general security of the country thus affecting international arrivals. According to Mayaka and Prasad (2012), the years 1998, 2003, and 2008 showed a decline in tourism numbers arrival due to elections held in Kenya in 1997, 2002 and 2007 respectively.

\subsection{Global Economic and Political Environment}

The tourism sector in Kenya is largely dependent on the revenue collected from international tourists, therefore, any event that is likely to interfere with the arrival of tourists in Kenya would have negative impacts on the sector. Any crisis or economic slowdown in the tourism source market affects the destination as it was the case in America in 2001 where there was a terror attack. The attack caused the demand for international air travel to shrinking by $17 \%-37 \%$ in the two years following the attack (De Sausmarez, 2013). This impacted the Kenya tourism industry since America is the leading source of tourists visiting Kenya accounting for $11.12 \%$ of total international arrivals in 2018 (GOK, 2019). The global economic crisis in 2008 also affected international arrivals significantly in many countries including Kenya. According to WTO (2013), the least impacts of the fall in international tourism arrivals were felt by countries with a diversified international tourism market.

\subsection{Wildlife Conservation Challenges.}

Tourism remains a very critical source of revenue in Kenya contributing about $11 \%$ of the gross domestic product (Mayaka \& Prasad, 2012). In Kenya, tourism is mainly wildlife-based with safari tourism bringing in a significant amount of tourism revenue. Inadequate lands for herding and agriculture have exposed the national parks to the danger of invasion by farmers. Increased agricultural activities and subdivision of lands around the game reserves and national parks have also raised instances of human-wildlife conflicts as wild animals' cross into adjacent private farms to look for pasture and water, therefore destroying plants and domestic animals. According to Okello (2014), approximately $70 \%$ of wild animals live outside protected areas like forests and national parks. The destruction caused by wild animals has increased the cost of conservation besides contribution to rural poverty. The threat of invasion of the national parks and forest ecosystem for settlement and farming continues to be a major threat to wildlife and therefore to a significant source of Kenyan revenue. A 2005 forest assessment in Kenya for instance established that a declining trend of forest cover between 1999 and 2005 respectively (UNDP-UNEP, 2006).

\subsection{Environmental Challenges}

Besides wildlife, the coastal beaches are an important attraction to tourists visiting Kenya every year. Although receiving a high number of tourists could have a positive economic impact, mass tourism could exert pressure on the natural resources especially on the environmentally sensitive areas and destroy the ecosystem (Atieno \& Njoroge, 2018). A case in point is discussed by Kanunah and Sindiga (1999) in Atieno and Njoroge (2018) where there was an environmental degradation of Malindi, a popular tourist port in Kenya as the environmental carrying capacity was exceeded. Mombasa has also experienced environmental challenges of solid waste and oil spillage on the ocean due to huge numbers of tourists visiting.

\subsection{Less Quality Products and Lack of Diversity}

Kenya's tourism market faces stiff competition from rival countries offering similar products and targets the same tourism market. Investing in high-quality products like hotels, beaches, etc., as well as diversifying the products will ensure that Kenya has an edge over the other competitors. According to GOK (2010), Kenya has a problem with tourism diversification with only seven parks receiving $80 \%$ of the total visitors. Besides, the quality of Kenyan infrastructure was determined to be wanting as only $18 \%$ of the hotel were of $4-5$-star standards compared to the average percentage of the world tourism destination hotels which stood at $40 \%$. Poor quality service, therefore, a major challenge to the Kenya tourism sector, thereby reducing the competitiveness of the destination visa viz other destinations.

\subsection{Less Quality Products and Lack of Diversity}

Also, the key to the tourism sector is the quality and safety of transport and communicating infrastructure including roads, railways, airports, and telecommunications. Inadequacies of the transport and communication networks acknowledged by the Ministry in charge of tourism in the national tourism policy GOK (2010) and investments in the sector to boost tourism is a key proposal. The government through the national tourism blueprint 2030, takes a number of infrastructural improvement actions to reduce time to the destination and increase the time at destination by improving the status of the existing international airports. The road networks to the regional tourism destinations and regional airports are also targeted for improvement to allow for easier and faster mobility (GOK, 2017). 


\section{Conclusion}

Tourism is undoubtedly an important economic sector in Kenya going by its annual contribution to the country's GDP. Despite this, the Kenya tourism sector is yet to reach its maximum potential due to the factors discussed above. Over-reliance on safari and beach tourism has prevented Kenya from exploiting other major tourism, of which vast is located in rural areas like cultural heritage. Diversifying tourism products is, therefore, key to accessing more international, regional and local markets as it increases the choice in the destination. This diversification should focus more on the rural areas which as discussed are underexploited. Improving the customer's experience in a destination is also key to ensuring that it remains competitive. Tourists must feel secure, safe and comfortable while visiting a tourist destination. Ensuring stability by protecting the country from both external and internal threats to security like terrorism, robberies, etc., is crucial in assuring tourists of their safety while visiting. The government should, therefore, put measures that would discourage foreign countries from issuing travel advisories to Kenya, thus affecting the flow of international tourists to the country. Having an over regional and international competitors also depends on the level of infrastructural investments in the sector, something that won't only ensure comfort to the visiting tourists, but also, reduce time wastage between destinations with a country. This could be achieved by improving the conditions of the roads with the destination and those linking major destinations, especially in rural areas. The hotels in the country should be of international standards by encouraging partnership with international brands and allowing internationally established companies to invest in the hospitality sector, thus, increasing the competitiveness of the sector vis-à-vis the competitors. Finally, exploiting the opportunities available could increase the presence of the country globally. The is located strategically, providing access to many landlocked countries like Uganda, Rwanda and Burundi making it "gateway to East". Many international organizations like UNEP and UN-Habitat are headquartered in Kenya, besides being an important regional aviation hub. All these opportunities could be harnessed to better the economy and strengthen the tourism sector.

\section{References}

Amir, A. F., Ghapar, A. A., Jamal, S. A., \& Ahmad, K. N. (2015). Sustainable tourism development: A study on community resilience for rural tourism in Malaysia. Procedia-Social and Behavioral Sciences, 168(116-122).

Anderson, E., Bakir, A., \& Wickens, E. (2015). Rural tourism development in Connemara, Ireland. Tourism Planning \& Development, 12(1), 73-86.

Atieno, L., \& Njoroge, J. M. (2018). The ecotourism metaphor and environmental sustainability in Kenya. Tourism and Hospitality Research, 18(1), 49-60.

Avraham, E., \& Ketter, E. (2017). Destination image repair while combatting crises: tourism marketing in Africa. Tourism Geographies, 19(5), 780-800.

Bebbington, A. (2001). Development: rural development strategies. International Encyclopedia of the Social \& Behavioral Sciences, 3578-3583.

Benur, A. M., \& Bramwell, B. (2015). Tourism product development and product diversification in destinations. Tourism management, 50, 213-224.

Binns, T., \& Nel, E. (2002). Tourism as a local development strategy in South Africa. Geographical Journal, $168(3), 235-247$.

Bramwell, B. (1994). Rural tourism and sustainable rural tourism. Journal of Sustainable Tourism, 2(1-2), 1-6.

Buigut, S. (2018). Effect of terrorism on demand for tourism in Kenya: A comparative analysis. Tourism and Hospitality Research, 18(1), 28-37.

Calatrava, J. (2016). Origin and evolution of rural development concept and policies: from rural communities to territories. Paper presented at the Old and new worlds: the global challenges of rural history: international conference.

Cánoves, G., Villarino, M., Priestley, G. K., \& Blanco, A. (2004). Rural tourism in Spain: an analysis of recent evolution. Geoforum, 35(6), 755-769.

Chantal. (2018). Kenya: Lamu, The Swahili Maulid Town with an International History, retrieved from https:/wayfaringgreensoul.com/kenya-lamu-the-swahili-maulid-town-with-an-international-history/

Cowan, T. (2010). An overview of USDA Rural Development programs. Washington, DC.

De Sausmarez, N. (2013). Challenges to Kenyan tourism since 2008: crisis management from the Kenyan tour operator perspective. Current issues in tourism, 16(7-8), 792-809.

Dijkstra, L., \& Poelman, H. (2014). A harmonized definition of cities and rural areas: the new degree of urbanisation. WP, 1,2014

Farah, I. (2006). The national museums of Kenya: Achievements and challenges. Museum International, 58(1-2), $19-28$.

GOK. (2010). Sessional Paper No. 1 of 2010 on Enhancing Sustainable Tourism in Kenya. Nairobi.

GOK. (2013). Sector Plan for Tourism 2013 - 2017. Nairobi: Government Printer. 
GOK. (2017). National Tourism Blueprint 2030 Nairobi: Government Printer.

GOK. (2018). Kenya Tourism Agenda 2018-2022. Nairobi: Government Printer.

GOK. (2019). Tourism Sector Performance Report - 2018. Retrieved from Nairobi: http://ktb.go.ke/wpcontent/uploads/2019/01/Tourism-Performance-2018-Presentation-Final2.pdf

Irandu, E., \& Shah, P. (2016). Development of cultural heritage tourism in Kenya. A strategy for diversification of tourism products. Dessier, A\& Njuguna, M. Conservation of Natural and Cultural Heritage in Kenya, $154-171$

Jafari, J. (1982). The tourism market basket of goods and services: the components and nature of tourism. The tourism market basket of goods and services: the components and nature of tourism., 1-12.

Jovanović, S., \& Ivana, I. (2016). Infrastructure as important determinant of tourism development in the countries of Southeast Europe. Ecoforum journal, 5(1).

Kanunah, M., \& Sindiga, I. (1999). Unplanned tourism development in sub-Saharan Africa with special reference to Kenya. Journal of Tourism Studies, 10(1), 25.

Kirori, G. N. (2015). Rural Development Policies in Kenya: A Descriptive Analysis Over 1970-2001 Period. European Journal of Business, Economics and Accountancy, 3(1), 35-53.

Kozak, M., \& Buhalis, D. (2019). Cross-border tourism destination marketing: Prerequisites and critical success factors. Journal of Destination Marketing \& Management, 14, 100392.

Liu, Z. (2003). Sustainable tourism development: A critique. Journal of Sustainable Tourism, 11(6), 459-475.

Lepp, A., Gibson, H., \& Lane, C. (2011). Image and perceived risk: A study of Uganda and its official tourism website. Tourism management, 32(3), 675-684.

Mafunzwaini, A. E., \& Hugo, L. (2005). Unlocking the rural tourism potential of the Limpopo province of South Africa: some strategic guidelines. Development Southern Africa, 22(2), 251-265.

Mayaka, M. A., \& Prasad, H. (2012). Tourism in Kenya: An analysis of strategic issues and challenges. Tourism Management Perspectives, 1, 48-56.

Muhwezi, D. K., Baum, T., \& Nyakaana, J. B. (2016). Dealing with negative symbolism of destinations with difficult heritage: Analysis of Uganda's image. Journal of Hospitality Management and Tourism, 7(3), 3342.

Nyaupane, G. P., White, D. D., \& Budruk, M. (2006). Motive-based tourist market segmentation: An application to native American cultural heritage sites in Arizona, USA. Journal of Heritage Tourism, 1(2), 81-99.

Odendal, A., \& Schoeman, G. (1990). Tourism and rural development in Maputaland: A case-study of the Kosi Bay area. Development Southern Africa, 7(2), 195-207.

Okech, R., Haghiri, M., \& George, B. P. (2015). Rural tourism as a sustainable development alternative: An analysis with special reference to Luanda, Kenya. CULTUR-Revista de Cultura e Turismo, 6(3), 36-54.

Okello, M. M. (2014). Economic contribution, challenges and way forward for wildlife-based tourism industry in Eastern African countries. Journal of Tourism and Hospitality, 3(1).

Paniagua, A., \& Moyano, E. (2007). Public right and private interest in selected recreation initiatives in rural Spain: a sociogeographical perspective. Tourism Geographies, 9(3), 275-295.

Pedford, J. (1996). Seeing is believing: the role of living history in marketing local heritage. In (pp. 13-20): Hisarlink Press, Enfield Lock.

Perlín, R. (2010). Theoretical approaches of methods to delimitate rural and urban areas. European Countryside, 2(4), 182-200.

Pizzoli, E., \& Gong, X. (2007). How to best classify rural and urban. Paper presented at the ponencia presentada en la Fourth International Conference on Agriculture Statistics.

Proença, S., \& Soukiazis, E. (2008). Tourism as an economic growth factor: a case study for Southern European countries. Tourism Economics, 14(4), 791-806.

Roberts, L., \& Hall, D. (2001). Rural tourism and recreation: Principles to practice: CABI.

Rogerson, C. M. (2012a). Strengthening agriculture-tourism linkages in the developing world: Opportunities, barriers and current initiatives. African Journal of Agricultural Research, 7(4), 616-623.

Rogerson, C. M. (2012b). Tourism-agriculture linkages in rural South Africa: Evidence from the accommodation sector. Journal of Sustainable Tourism, 20(3), 477-495.

ROK. (2010). The Constitution of Kenya, 2010. Nairobi: Government Printers.

ROK. (2019a). 2019 Kenya Population and Housing Census: Volume I Population by County and Sub-County Nairobi: Government Printer.

ROK. (2019b). 2019 Kenya Population and Housing Census: Volume III Distribution of Population by Age, Sex and Administrative Units Nairobi: Government Printers.

ROK. (2019c). 2019 Kenya Population and Housing Census: Volume IV Distribution of Population by SocioEconomic Characteristics Nairobi: Government Printers.

Rotich, D. J. (2012). An analysis of the challenges facing cultural tourism development in Kenya.

Saarinen, J., \& Lenao, M. (2014). Integrating tourism to rural development and planning in the developing world. 
Development Southern Africa, 31(3), 363-372.

SED Adventures. (2018). SED Adventures Tours \& Safaris Ltd. - Tanzania, Kenya and Uganda Travels. Retrieved from https://www.sedadventures.com/destinations/view/lake-nakuru-national-park.

Seetanah, B., Juwaheer, T., Lamport, M., Rojid, S., Sannassee, R., \& Subadar, A. (2011). Does infrastructure matter in tourism development? University of Mauritius research journal, 17(1), 89-108.

Sharpley, R. (2002). Rural tourism and the challenge of tourism diversification: the case of Cyprus. Tourism management, 23(3), 233-244.

Sharpley, R., \& Roberts, L. (2004). Rural tourism-10 years on. International Journal of tourism research, 6(3), 119-124.

Sharpley, R., \& Sharpley, J. (1997). Rural tourism. An introduction: International Thomson Business Press.

Smith, M. K. (2015). Issues in cultural tourism studies: Routledge.

Smith, S. (1994). The tourism product. Annals of tourism research, 21(3), 582-595.

$\mathrm{Su}$, B. (2011). Rural tourism in China. Tourism Management, 32(6), 1438-1441.

Swarbrooke, J. (1999). Sustainable tourism management: Cabi.

UN. (2019). 2018 Demographic Year Book. Retrieved from New York:

UNDP-UNEP. (2006). Poverty and Environment Initiative - Kenya: Poverty and Environment Issues: Governance Institutions, Institutional Frameworks and Opportunities for Communities. Retrieved from https://www.unpei.org/sites/default/files/e_library_documents/kenya-poverty-environment-issues.pdf

Weidenfeld, A. (2018). Tourism diversification and Its Implications for smart Specialisation. Sustainability, 10(2), 319.

Wishitemi, B., \& Okello, M. M. (2003). Application of the protected landscape model in southern Kenya. Parks, $13(2), 12-21$.

World-Bank. (2010). Kenya's Tourism: Polishing the Jewel. Retrieved from Kenya:

WTO. (2013). Economic Crisis, International Tourism Decline and Its Impact on the Poor: World Tourism Organization.

Xu, C., Jones, C., \& Munday, M. (2019). Tourism inward investment and regional economic development effects: perspectives from tourism satellite accounts. Regional Studies, 1-12.

$\mathrm{Xu}$, J. B. (2010). Perceptions of tourism products. Tourism management, 31(5), 607-610.

Collins Ouma Agayi received bachelor's degree in urban and regional planning from University of Nairobi, Nairobi, Kenya in 2015 and master's degree in city and regional planning from Selcuk University, Konya, Turkey in 2019. He is currently pursuing Ph.D. degree in city and regional planning at Konya Technical University, Konya, Turkey. His research interests include rural poverty and rural development. 